\title{
On perceptive teaching in Chinese middle school English teaching
}

\author{
Lifen $\mathrm{He}$ \\ Foreign Language and Culture Department, North Sichuan Medical College, Nanchong, Sichuan, China
}

\begin{abstract}
The traditional Chinese English teaching mainly emphasizes the learners' cognitive development which is not adaptable to the modern English class. The research of perceptive teaching improves not only learners' cognitive abilities but also their affective factors and helps learners develop their cognition and affect harmoniously. This thesis introduces the theoretical basis, instructional orders, principles, characteristics and objectives of perceptive teaching. Perceptive teaching can provide the middle school English teaching in China with some new principles and methods.
\end{abstract}

Keywords: perceptive teaching; Chinese; Middle school English teaching

\section{INTRODUCTION}

The Chinese middle school English has got lots of achievements. It has experienced several periods of reforms. The latest reform is in 2002. It emphasizes the learners' autonomous learning, learning strategies and emotional education. Perceptive teaching is suitable to the reform of the basic education in English teaching.

\subsection{English perceptive teaching can help learners' cognition and affect develop harmoniously}

For a long time in China, English language teaching (ELT) greatly emphasizes learners' cognitive development. Teachers' explanation is often based on the model that includes reading new words, explaining grammatical points, and analyzing complex sentence structures. It is more like the process of developing learners' cognitive abilities including memorization and analysis. In fact, cognition involves more aspects: thinking, problem solving, classifying, and creativity (Salovey and Sluyter, 1997: 3-10). Learners' affective development is neglected in ELT. The learners are passive in the whole learning process and lack of the chance to express their own ideas. The inharmonious relationships between cognition and affect---the emphasis on learners' cognitive abilities and the neglect of their affective aspects results in the inefficiency of ELT in China.

*Corresponding author: hlfsally@163.com.
In the reforms of basic education learners are regarded as the subjects of instruction. An Outline of Basic Education Curriculum Reforms (OBEC) (2001) requires that "teachers should change the ways of cramming knowledge into learners and find new ways to help learners shape active attitudes towards learning." Moreover, one of the teaching goals is to develop learners' affective education in English Curriculum Standard (ECS). Have these new approaches been applied in ELT? A survey made before the experiment surprised the author greatly: $80 \%$ of the subjects think that the purpose of learning English is to get good marks in the exams; $60 \%$ think that they have to learn English; only 20\% claim that they learn English because they like English very much. Learners' needs are still ignored in ELT. It shows that there still exists the problem that learners' cognition and affect are inharmonious in some middle schools.

Perceptive teaching emphasizes not only learners' cognitive abilities but also their affective factors and it can help learners develop their cognition and affect harmoniously.

\subsection{Perceptive teaching can carry out new approaches in OBEC and ECS}

OBEC (2001) puts forward: "learners can change their own learning aptitudes, develop effective learning strategies and promote their autonomous learning by observing, experiencing and doing". ECS claims that learners' affective factors can greatly affect their 
all-round development. $O B E C$ proposes that if learners can get information through discovering, they will be confident of their future study. The learning process by doing or experiencing is a perceptive process. But in traditional teaching teachers mainly emphasize mechanical training and overlook learners' perceptive abilities including cognitive factors and affective factors. Therefore, perceptive teaching is the necessity to carry out the new approaches in $O B E C$ and $E C S$.

\subsection{Perceptive teaching can be helpful for teachers with poor abilities}

In modern English classes learners learn by doing or practising as much as they can, which requires the teachers to be good at speaking and listening. But most English teachers learned English in the traditional ways emphasizing only reading and writing. Some middle school English teachers are lacking in the abilities of controlling the whole class. Perceptive teaching can give them some suggestions and provide them with a useful teaching model.

\subsection{Perceptive teaching is suitable for new textbook}

The new English textbook for junior middle school is titled Go for It!, published by People's Education Press and Thomson Learning. In each unit, there are four parts: section A introduces some useful expressions, sentence patterns and grammar focus; section B introduces more useful expressions and further study of the sentence patterns; the third part is self-check and the fourth part is a reading passage. It can be learned through the instructional orders of perceptive teaching: collecting, recognizing, discovering, comprehending, and consolidating.

The purposes of this thesis are to test whether English perceptive teaching can be helpful for middle school English teaching, and whether it can help learners develop their cognition and emotion harmoniously. Some teachers realize the importance of emotional education, but they think that it is hard to judge whether learners can achieve the emotional goals. This research can help learners change their attitudes or personal characteristics and stimulate learners' interest and motivation. Teachers can follow this model to improve learners' affective development.

\section{COGNITION, AFFECT AND PERCEPTION}

\subsection{Cognition and affect}

Learners' learning process is regarded as a cognitive process. Cognition is the psychological process of people's acquiring new information including strategies of perception, memory, imagination, and mind. Besides these aspects, cognition should also include "thinking", "recognizing", and "classifying". In recent years, because of the emphasis on learners' individual factors "problem solving" and "creativity" are regarded as important cognitive abilities in the fascinating functions of the mind. Learners' cognitive development is regarded as one of the important goals to achieve in instruction. Bloom (1956) identifies six types of cognitive learning as the educational objectives: knowledge, comprehension, application, analysis, synthesis and evaluation. In order to achieve these educational objectives, several decades ago Norman (1980: 243) stresses the need for the teachers to become cognizant of students' acquiring, storing, retrieving, and using knowledge. Based on these researches, the cognition in the new curriculum refers to memory, perception, imagination, thinking, classifying, problem solving, observation, judgment, comparison and so on. Learners' observation, comparison, language transfer, judgment, generalization, and comprehension will be tested in the experiment.

Affect refers to emotion or feeling. Damasio (1994: 145) makes a distinction between the terms emotions (changes in body state in response to a positive or negative situation) and feelings (perception of these changes). The mood and attitude still control learners' behavior besides emotion and feeling. Learners' value is another important factor in affect. Krathwohl, Bloom and Masia (1964: 136) describe learning as a process of "receiving, responding and valuing" through learners' value systems. At present, affective factors generally include interest, empathy, extroversion, anxiety, attitude, and motivation (Wang, 2000: 156). Affect in the new English curriculum has a broader meaning. It refers to not only learners' value, interest, empathy, extroversion, anxiety, attitude, and motivation but also their own experience of love, happiness and success. In the experiment learners' learning concept, motivation, interest, and attitude are tested in questionnaire.

It should be noted that the learners' affective side is not in opposition to their cognitive side. Stevick (1998: 7) speaks of bringing to language teaching a concern for "deeper aims", for "pursuing new life goals", not just for reaching certain "language goals". The affective aspects can lead to more effective language learning. Learners' learning is a unit of the two. Greenhalgh (1994: 27-28) regards emotion and cognition as partners in the mind and he insists that it is better "to reunite cognition and emotion in the mind." Therefore, teachers need to be concerned with learners' cognitive and affective needs.

Cognitive factors include affective aspects and affective factors include cognitive aspects. Take "attitude" for example. It is cognitive for it expresses learners' thoughts and it is affective for it has feelings and emotions attached to them. Learners' cognitive development and affective development are indispensable.

Cognition has a great effect on affect. Cognition can make learners generate emotion. Only when people 
realize the essence and implied meaning of knowledge do they generate. For example, people have different feelings when seeing tigers in the wild forest and in the zoo: in the wild forest they feel frightened and nervous while in the zoo they do not. The reason is that they have different emotions to their environment. Cognition can also change learners' emotion. Learners emotion can be enriched and developed from low level to high level with their higher cognitive abilities. Their cognitive structures will affect their judgment, evaluation and self-concept.

Affect has an effect on learners' cognitive abilities. It is evident that strong positive or negative emotions are involved in the success or failure of language learning. Castillo (1995: 17) claims that emotion will accelerate or prohibit learners' cognitive development. Wang (2000: 174) expresses that facilitative anxiety is a positive factor and it is useful and necessary for language learning while debilitative anxiety is a negative factor and it may hinder the process of successful second language learning. The afflictive emotions tend to make one ill and the wholesome states of mind tend to promote health.

Teachers should deal with the relation between cognition and emotion in English teaching. The teaching goals are not only to improve learners' cognitive abilities but also to improve their learning interests.

\subsection{Perception and cognition}

There is no suitable term in English for 感悟式教学 in Teaching English as a Foreign Language (TEFL). Perception is the ability to recognize familiar persons, objects, or events with meaning and expectations. Besides recognition, it still refers to the understanding of events, objects, and stimuli through the use of senses (sight, hearing, touch, etc.). That is to say, perception includes two aspects: one is "recognition"; the other is "comprehension". That is to say, perceiving something means that you can recall past experiences with this person, object, or event; you experience meaning; and you can understand the person, object, or event. Perception also can give us information about our environment and it can enable us to form beliefs or make judgments about how things are in our surroundings. Therefore, the author chooses the term “perceptive teaching” because 感悟式教学 in TEFL emphasizes two points of learning: One is the recognition of knowledge, the other is the comprehension. Recognition in perceptive teaching not only means "recognizing prior knowledge" but means teachers' presenting new knowledge based on prior knowledge as well.

Perceptive process is a cognitive process. Cognitive process includes the fascinating functions of the mind--recognition, memory, thinking, problem solving and creativity. Perception is the bridge between external knowledge and learners' cognition. The learning process is the process of recognizing, memorizing, and comprehending of new knowledge through perception.

Perceptive teaching emphasizes learners' cognitive abilities such as judgment, classification, and generalization. Learners acquire new knowledge after collecting plenty of information in perceptive teaching. They have to select and classify useful information. Perceptive teaching also emphasizes learners' autonomous learning which encourages learners to participate in discovering new knowledge. Autonomous learning can develop learners' abilities of problem solving. Perceptive teaching can change learners' cognitive structures. Perceptive teaching emphasizes the integration of prior information and new information.

\subsection{Perception and affect}

Perceptive process is a cognitive process with affective factors because learners' cognitive development and their affective development are inseparable. Affect in perceptive teaching contains learners' interests, prior experience, successful learning experience, and the emotions implied in the text. Learners' affective development is one of the goals to achieve in perceptive teaching. Stimulating the different positive emotional factors, such as self-esteem, empathy or motivation can greatly facilitate the language learning process. Beyond the language instructional goal, language teaching will develop and grow for whole person education. We would also argue that it has a moral purpose which must incorporate a sense of values.

Of course attention to affect does not mean that all the problems in language teaching can be solved. It does not mean that learners' cognitive activities can be ignored, either. Learners acquire their knowledge mainly by means of their cognitive abilities and the development of the learners' affect is also beneficial for learners' cognitive development."

\section{PERCEPTIVE TEACHING}

The philosophical foundations for perceptive teaching can be traced to the fifth century B.C. when Socrates developed a systematic method of discovering truth through combining questioning and logical reasoning. The "Socratic method" consists of asking a pupil about a particular circumstance and leading him to a general definition of a virtue by skillful questioning.

Another founder of perceptive teaching is Confucius, the most famous ancient Chinese philosopher, educator and founder of Confucianism during the later Spring and Autumn period (722-481 B.C.). Confucius tells us to teach students in accordance with their aptitude. It is an important core in Confucianism that after learning something learners can solve the problems related to it through comprehension. His ideas influence the education in China greatly. 
Although there is no term of "perceptive teaching" in western language teaching, some teachings still emphasize learners' cognitive development and affective development, such as Total Physical Response Method(TPR), the Silent Way Method, Suggestopedia Method and so on.

TPR endeavors to teach language through physical activities. Its core of learning theory is comprehension. Besides comprehension, it also emphasizes that learners' real needs and reduction of stress are important for successful language learning. But TPR overlooks emotions implied in the text. TPR has the only grammar-based view of language. Asher (1977: 354) explains this clearly: "most of the grammatical structure of the target language and hundreds of vocabulary items can be learned from the skillful use of the imperative by the instructor." In modern English teaching the goals of learning should contain language skill, culture, learning strategy and grammar.

In Silent Way Method, learners themselves are frequently silent so that they can have time to discover, analyze, test and remember the language being taught. The Silent Way Method shares the same principle of successful learning experience in perceptive teaching. Successful learning involves commitment of the self to language acquisition through the use of silent awareness. It also shares the principle of discovery learning. Known as discovery learning, the Silent Way sees learning as a process of problem-solving, discovering, and creative activity. The disadvantage of this method is the indirect role of a teacher. Learners will sometimes feel puzzled with teachers' minimal help.

In Suggestopedia Method, classroom activities are composed of visualization, role play and listening to the texts read by the teacher or accompanied by music. It emphasizes learners' affective factors and holds that learning is achieved in a relaxed and comfortable environment. But the method merely emphasizes the memorization of vocabulary in learning. Suggestopedia Method suggests a view of language in which lexis is central and lexical translation rather than contextualization is stressed.

With the reforms in basic education in China, researchers have done some researches about Chinese perceptive teaching. In reading, $\mathrm{He}$ (2013) points out that learners can read in a certain circumstance with individual factors and affective factors, emphasizing learners' own experience; Ge (2015) argues that teacher-centered method should be changed into learner-centered in reading. Some researchers do further research in Chinese perceptive teaching systematically. Lai (2012) points out the principles, aims and design of Chinese perceptive teaching and analyzes how to develop learners' perceptive abilities in Chinese teaching.

Researchers have also done some researches in English perceptive teaching. They are interested in the ways to develop learners' perceptive abilities. He (2013) puts forward the ways to develop learners' perceptive abilities by means of learners' mental activities and learning strategies. Lai (2012) proposes that learners' reading abilities should be improved by perceiving sentence patterns. Liu (2003) claims that if the learner's interests are greatly stimulated they can be happy to learn.

Although researchers have already done some researches in perceptive teaching theoretically, it is non-systematic. Therefore, this thesis will introduce English perceptive teaching systematically.

\subsection{Theoretical bases of English perceptive teaching}

Perceptive teaching is not only based on practice but scientific theories as well. It is the combination of the theories and practice.

\subsubsection{Bruner's discovery learning}

Jerome Bruner's (1966: 284) work emphasizes the structure of a subject being studied, the need for active learning as the basis for true understanding, and the value of inductive reasoning in learning. In order to grasp the structure of information, students must be active---they must identify key principles for themselves rather than simply accepting teachers' explanations. Bruner calls it "discovery learning" .Discovery learning in perceptive teaching means discovering not only the structure of knowledge but also the implied meaning or values in the context.

Teachers should present examples until learners discover the interrelationships---the knowledge. The classroom learning should take place through inductive reasoning, that is, by using specific examples to formulate a general principle. In the discovery process teachers can present some directions. Students are presented with intriguing questions, baffling situations or interesting problems. Instead of explaining how to solve the problem, teachers can provide appropriate materials, and encourage students to make observations, form hypotheses and test solutions. Some researchers introduce some guidelines to apply Bruner's ideas (Lefrancois, 2004: 285):

- Present both examples and non-examples of the concepts you are teaching

- Help students see connections among concepts

- Encourage students to make intuitive guesses

1. Instead of giving a word's definition teachers say: "Let's guess what it might mean by looking the words around it.

2. Give students a map of ancient Greece and ask them where they think the major cities were

3. Don't comment after the first few questions. Teachers wait for several ideas before giving the answer

4. Use guiding questions to focus students when their discovery has led them too far away.

The discovering process is the learners' experiencing process, in which learners recognize, comprehend, 
discover and recreate knowledge.

\subsubsection{Humanistic psychology}

Rogers (1969: 35) emphasizes learners' "self- actualization" and "fully functioning". Human beings have a natural tendency towards actualization including the growth and fulfillment of basic potentialities. Human beings basically need and want both personal fulfillment and close, intimate relationship with others. To function fully is to function in a total organism way and it is not only intellectual, self-conscious functioning. Rodgers (1969: 35) believes that conscious and rational thought is not an effective means of arriving at life's decisions and points out that "man is wiser than his intellect". This is not to degrade human ability to reason but to mean that humans function optimally when they are unified organisms rather than solely cognitive, self-consciously rational human beings.

In education, the teachers should be facilitating of learning, providing an atmosphere of freedom and supporting for individual development. They should be genuine, accepting and emphatic. Learning which is self-initiated and which involves feelings as well as cognition is most likely to be lasting and pervasive.

\subsubsection{Constructivist learning theories}

Constructivism thinks individuals are actively involved right from birth in constructing personal meaning, that is, their own personal understanding or their experience. In other words, everyone makes their own sense of the world and the experiences that surround them. In this way, learners are brought into central focus in learning theory.

Piaget (1963: 84-91) mentions that learners construct their meanings by the complementary process of assimilation and accommodation. When learners receive language input, for example, listening to a conversation, they need to modify what they have already known about the language (accommodation) so as to "fit" the new information into their existing knowledge (assimilation). In this way learners' knowledge structures gradually develop.

The teacher cannot tell students what concepts to construct or how to construct them, but by judicious use of language in directions which the teacher consider useful. In recent years, there has been a considerable amount of interest in this approach about the use of problem-solving tasks in ELT. In perceptive teaching teachers encourage learners to learn by solving problems.

In language teaching constructivists suggest two principles of learning. One is that learning should start with the learners' attitudes and interests which they bring to the learning situation. The other is that learning can result from the interaction between learners' characteristics and experience in such a way that learners construct their own understanding from the inside.

\subsection{Instructional orders of English perceptive teaching}

In perceptive teaching, different teachers may carry out different instructional orders. Zhang (2005) proposes that there are five instructional orders: collecting new information, presenting, cooperating by practice, discovering knowledge and presenting learning experience. Hong (2002: 15) claims that there are three steps in perceptive teaching in terms of language goals: acquiring knowledge, acquiring emotions and reflecting. Based on their researches and the experimental research, five instructional stages in perceptive teaching are: collecting, recognizing, discovering, comprehending, extracting and distilling.

(1) Collecting. In this stage, teachers and learners collect as many materials related to new information as possible, which gets ready for teaching and learning. They can gain new information by looking up reference books, recalling their prior experience, surfing the internet and so on. Thus learners can participate in learning actively. This is helpful to develop learners' abilities to collect and deal with information.

(2) Recognizing. Both teachers and learners present their materials in the appropriate ways. Most materials that they collect are based on their prior knowledge or experience. In this stage learners recognize new information based on prior knowledge or experience without being given deep impressions. Teachers should encourage learners to recognize new information through asking questions, drawing pictures, listening to music, discussing and so on, which purpose is to stimulate their interests.

(3) Discovering. In this step learners discover new information through independent thinking based on their prior knowledge or experience. Teachers must give learners enough time to discover new knowledge in a "real" circumstance. During discovering process, teachers can give some clues to enlighten learners to acquire knowledge if they have difficulties in discovering. Besides this teachers should help learners discover values implied in the new information. At the end of this process, teachers should give learners feedback in time. As learners discover new language knowledge and values, they will acquire successful learning experience which can stimulate their interests in learning.

(4) Comprehending. In the former stage learners discover new language knowledge and values based on their prior knowledge and experience. Because of learners' cognitive structures, they may discover new information incompletely or superficially. Teachers are helpful for learners to grasp the clues of language learning. Learners will have deeper thoughts and understanding of new information if they have general ideas about new knowledge. Therefore, their cognitive structures and knowledge structures will change.

(5) Extracting and distilling. Based on the above four stages learners may understand new knowledge 
such as grammar knowledge, and implied knowledge such as values in the text but they may not completely master it. Therefore, it is necessary to extract and distill the essential meaning including grammar knowledge, implied knowledge, learning experience and so on. In this process, both teachers and learners can draw a conclusion about learning and present learning experience. In this way their new knowledge structures can also be consolidated. Their successful learning experience can make them study further.

\subsection{Principles of English perceptive teaching}

\subsubsection{English perceptive teaching should be related to real life.}

The immersion program in Canada provides the author with enlightenment. It is likely to be more successful than conventional language teaching as a subject because the language is treated in school as a medium rather than as a subject. Perceptive teaching is required to be related to learners' real life, which means that English is treated as a "medium" in English class. In this curriculum, learners can be regarded as the subjects in class and gain their own learning experience.

\subsubsection{English perceptive teaching should be related to practice}

The learners should be the centre in class and they should learn by doing. In the process of learning by doing learners' creativity and imagination can be greatly developed. They can gain more knowledge by practicing than from books. Learners' activities should be related to their interests. Dewey' (1938) definition of "educative" expounds the relation between education and learners' interests: "the child realizes his own impulse (interests) by recognizing the facts, materials and conditions involved, and then regulates his impulse through that recognition." (qtd. in David, 1984: 23). Learners' activities can stimulate their interests, improve their comprehension of new information, and consolidate their understanding.

\subsubsection{English perceptive teaching should be related to learners' feelings}

Ellis (1994: 293) identifies four factors in learners' feelings: language aptitude, learning styles, motivation, and personality. In perceptive teaching learners' feelings can be classified into two kinds: one is the emotions in the text book such as life values, morals and so on; the other is the learners' feelings such as their spirit to overcome difficulties, their successful learning experience, their cooperative spirit, etc.. Both the emotions inside the books and those outside the books are empathized in perceptive teaching. The former feelings have a great effect on learners' life and the latter can help learners solve problems.

\subsubsection{English perceptive teaching should be related to whole person education}

In the traditional English class teachers mainly focus on learners' learning language but ignore learners themselves. It is important for teachers to empathize their learners by getting to know them as individuals and seeking to understand the ways in which they make sense of the world. Humanistic education starts with the idea that students are different, and it strives to help students become like themselves and less like each other. The whole person education mainly contains learners' cognitive development and affective development. English perceptive teaching holds the approach that education is not only the process to acquire knowledge but also the process to develop learners' cognitive aspect and affective aspect. Its goal is to develop learners wholly.

\subsection{Characteristics of English perceptive teaching}

\subsubsection{Holistic}

In perspective teaching especially in reading, learners are required to read wholly to acquire the implied meaning in the passage. Gestalt psychologists hold the approach that the whole part is more effective than the integration of discrete items. The view that what is to be learned can be broken down into small subcomponents and taught as discrete items and skills is not helpful for the learners to study. Instead the meaning should constitute the central aspect of any unity of study. Moreover, any unity of study should be presented in all its complexity rather than be presented in isolation.

\subsubsection{Proper input}

$\mathrm{i}+1$ is a concept associated with the natural approach, which rests on the premise that there is a natural order for language acquisition and that learners will acquire a structure when ready for it. What is important is that the input of language should neither be so far beyond their reach that they are overwhelmed such as " $\mathrm{i}+2$ ", nor so close to their current stage that they are not challenged at all such as " $i+0$ ". In perceptive teaching, learners should be given proper input. Learners' active reaction to teaching shows that language input is nearly " $i+1$ ". Otherwise, it is not enough or too much.

\subsubsection{Learner-centered}

Learning process should be suitable for meeting the students' needs. The classroom teachers are faced with actual individuals in a real place in real time and they may find the relation between the curriculum and the needs of their particular learners.

In traditional language teaching, teachers following the textbook provide students with what they should know. If learners can demonstrate what they should master at the end of a course they can receive good marks. Besides language knowledge teachers have to 
know the degree to which learners have already known the target language in perceptive teaching. The importance of learners' views is also recognized in perceptive teaching. Learners' views can be discovered by means of questionnaires, diaries, observations and interviews. Learners' individual factors such as attitude, motivation, and self-confidence are still emphasized.

\subsubsection{Autonomous learning}

In language teaching, learner autonomy is that the learners should be encouraged to assume a maximum amount of responsibility for what they learn and how they learn it. In perceptive teaching learners acquire knowledge mainly by practice or experience. Learners can achieve cognitive and affective goals through autonomous learning.

\subsubsection{Process Consciousness}

In traditional English teaching what teachers do is to help learners achieve good scores for product is overemphasized. In perceptive teaching, Process and product are not contrary but complementary. Product can show a clear result but it may have an incomplete evaluation of learning. Process can give a complete evaluation of learning. Learners achieve their moral goals during learning process in perceptive teaching. Learning process includes learners' cognitive process and affective process. In the learning process learners can be treated as "whole persons".

\subsubsection{Leaning by Doing}

Learners' activities play an important role in English perceptive teaching. In perceptive teaching learners form their own experience based on their prior experience. Learning activities can also provide learners with plenty of learning experience. They can participate in the instructional activities by doing. The process of learning by doing can stimulate learners' creativity. In learning learners' cognitive structures will change gradually as they gain more and more knowledge.

\subsubsection{Creative}

Learners acquire knowledge in perceptive teaching by discovering. In teaching teachers should give learners enough time to discover new knowledge. In the discovering process learners can find some ways to discover it. They can discover not only the knowledge in books but also the values or philosophy outside the books. This process is a creative one.

\subsection{Instructional objectives of English perceptive teaching}

Usually, there are five objectives guide classroom instruction: language, strategy, affect, philosophical thought, and methods or process. Generally speaking, the goal of perceptive teaching is to supply learners with an all-round education including learners' cognitive improvement and affective improvement. Cognitive objectives generally refer to the improvement of language skills, which is the core of second language teaching while affect generally refers to the changes in learners' attitudes or behaviors.

\subsection{Instructional evaluation of English perceptive teaching}

Testing is not equal to evaluation. Testing is different from evaluation and is one way to evaluate. It cannot take place of evaluation. Non-testing means of evaluation contains classroom observation, portfolios, journals, questionnaire, interview, and students' conference. Testing is not enough for instructional evaluation. Learners' affective development should be included in the instructional evaluation of perceptive teaching as well as their cognitive development. Therefore, three aspects are included: instructional activities, teaching and learning.

The evaluation of instructional activities consists of three parts: the evaluation of instructional objectives, the evaluation of instructional process and the evaluation of instructional results. From Instructional Objectives, Teachers can grasp key points and difficulties in the textbook and give learners clear and detail objectives according to instructional plan, textbook and learner. From Instructional Process, in perceptive teaching, teachers should give learners enough time for them to comprehend language knowledge that learners are expected to acquire in the classroom. Perceptive teaching should also focus on learners' affective factors. Teachers are supposed to stimulate learners' interests, attitudes, or motivation to learn English. The learning atmosphere should be harmonious and democratic. From Instructional Results, Teachers and learners should accomplish the instructional objectives and tasks. Learners' language skills can be improved greatly. Their cognitive structures will change. English learners show great interests in learning English. Their attitudes, values, or beliefs will change, too. Above all, learners' learning methods can be more adapt for them.

The evaluation of teachers' teaching in perceptive teaching is composed of three aspects: teaching principles, teaching content and teaching method. Teachers should respect students, give them confidence in learning, and encourage them to overcome difficulties. Teachers should grasp and present teaching content properly and correctly. In any case, teachers should regard learners as the subjects in class. Teachers should help learners learn by doing and they can change their teaching method with different learners.

The evaluation of learners' learning in perceptive teaching consists of learning process and learning results. Learners should take an active part in class. Not everyone can have the chance of answering ques- 
tions or reading texts individually but teachers should pay attention to have as many learners join in instructional activities as possible. Learners' all-round development consists of their cognitive development and affective development. Learners can achieve language objectives and affective objectives in perceptive teaching through independent learning. Independent learning means that learners can express their own or different ideas independently.

Perceptive teaching began to appear when the reforms in basic education started. Though some research has been done in this field, researchers haven't introduced it systematically. The purpose of perceptive teaching is to develop learners' cognition and affect harmoniously. Then, the author briefly introduces some aspects of English perceptive teaching: its theoretical bases, instructional orders, principles, characteristics, and evaluation. Therefore, readers can have a clearer picture of English perceptive teaching.

\section{REFERENCES}

[1] Asher, J. 1977. Learning Another Language Through Actions: The Complete Teachers' Guide Book. Los Gatos California: Sky Oaks Production, pp.354.

[2] Bloom, B.E. 1956. Taxonomy of Education Objectives: Classification of Education Goals. Handbook I: Cognitive Domain. New York: David Mckay Company, Inc.

[3] Bruner, J. 1966. Toward a Theory of Instruction. Cambridge, MA: Belknap Press, pp.260-265+284.
[4] Castillo, A.G. 1995. Left--handed Teaching: Lessons in Affective Education. New York: Praeger, pp.17.

[5] Damasio, A. 1994. Descartes' Error: Emotion, reason and Human Brain. New York: Avon.

[6] Norman, D.A. 1980. Cognitive Engineering and Education. Hillsdale, NJ: Erbaum, pp.243.

[7] Dewey, J. Experience and Education. In David, A. (editor) 1984. Experiential Learning: Experience as the Source of Learning and Development. New Jersey: Prentice-Hall, 1938:23.

[8] Ellis, R. 1994. The Study of Second Language Acquisition. Oxford: Oxford University Press, pp.293.

[9] Ge Jingjing. 2015. Chinese Perceptive Teaching. Chinese Teaching and Research Journal, 6.

[10] Greenhalgh, P. 1994. Emotional Growth and Learning. London: Routledge, pp.27-30.

[11] He Lifen. 2013. Perceptive teaching in English reading teaching. Journal of Teaching and Management, 4.

[12] He Lifen.2013. An empirical study of perceptive teaching in college English teaching. Journal of South West University of Science and Technology, 5.

[13] Hong Xianli. 2014. Perceptive teaching strategies in the educational psychology of college education. Journal of Chongqing Normal University, 5.

[14] Lefrancios, G.R. 2004. Theories of Human Learning: What the Old Man Said. Beijing: Foreign Language teaching and Research Press, pp.284-285.

[15] Lai Xiuyun. 2012. The characteristics and strategies of chinese perceptive teaching in middle school. Journal of Chinese Learning, 5.

[16] Piaget, J. 1963. The Psychology of Intelligence. New York: Harcourt, Brace \& World, pp.84-91.

[17] Rogers, C.R. 1969. Freedom to Learn. Columbus, Ohio: Charles Merrill, pp.35+38-39.

[18] Stevick, E.W. 1998. Working with Teaching Methods: What's at Stake?. Boston: Heinle, pp.7. 